ANALYSIS

\title{
An unblinkered view of best interests
}

\author{
Wayne Martin and colleagues argue that decisions about patients' best interests must sometimes \\ take into account the interests of others
}

\begin{abstract}
Wayne Martin professor of philosophy, Fabian Freyenhagen reader in philosophy, Elizabeth Hall consultant in palliative medicine (retired), Tom O'Shea senior research officer, Antal Szerletics senior research officer, Vivienne Ashley postgraduate research assistant
\end{abstract}

Essex Autonomy Project, School of Philosophy and Art History, University of Essex, Colchester CO4 3SQ, UK

Doctors often find themselves in circumstances where they must make decisions on behalf of an incapacitated patient. As a matter of both ethics and law, such decisions must be taken in the best interests of the patient, but uncertainty remains about what is meant by best interests, especially in relation to the interests of others. Should the interests of others enter into a determination of the patient's best interests? We believe that they should and argue against a recent trend to focus solely on the patient.

\section{Interests of patients are not confined to self}

It only takes a moment's reflection to appreciate that the interests of one person are often wrapped up with the interests of others. A patient has an interest in recovering from her illness, but so do her family, employer, care providers, etc. Sometimes these various interests can be independently specified, but in other cases they are inextricably intertwined. Suppose that I am a single parent whose overriding interest is to ensure the wellbeing of my children. In that case the proper specification of my best interest is a function of theirs; I simply cannot determine the one without considering the other. This can create an ethical problem in medical decision making. In circumstances where medical staff must make a decision in the best interests of an incapacitated patient, to what extent can or should they take account of the interests of other people whose lives are affected by the outcome?

These ethical issues have taken on a concrete legal shape in the UK with the implementation of the Mental Capacity Act 2005, which specifies that, "An act done, or decision made, under this Act for or on behalf of a person who lacks capacity must be done, or made, in his best interests." However, the act proposes no definition of best interests. Accordingly, part of the challenge of applying the act is to interpret the best interests standard. This requires us to take a stand on the extent to which best interests should be interpreted individualistically.

\section{Individualism and hyperindividualism}

The courts are the ultimate arbitrators of how the best interests standard applies to particular cases, but anyone might have to assess the best interests of someone in their care. The task of providing guidance definitions for care providers has fallen to a variety of government agencies and third sector organisations. One publication from the Office of the Public Guardian, which provides advice on mental capacity to the public and health professionals in England and Wales, offers the following explanation: "Anything done for a person who cannot make decisions for themselves must be in their best interests. This means thinking about what is best for the person, and not about what anyone else wants."

A guidance pamphlet on financial decision making commissioned by the Department of Health and the Social Care Institute for Excellence, and published by the Mental Health Foundation, takes a similar tack: "When decisions are made for someone they must be made in their best interests. This means that what is decided must be best for that person and not what someone else wants."

These definitions are not intended to be ethically rigorous; nor are they legally binding. Nonetheless, we believe that they both reflect and reinforce a worrying trend in the public understanding of best interests. When conducting staff training we have seen some clinicians use a hand gesture suggestive of blinkers in dismissing questions about the effect on third parties: "The family's problems are not our responsibility; we've got to keep our focus exclusively on the patient." In our public policy work, we have repeatedly heard both legal and medical professionals express the view that the Mental Capacity Act requires such an approach. ${ }^{3}$

In interpreting this trend, we find it useful to adapt the sociological notion of hyperindividualism. ${ }^{4} \mathrm{~A}$ best interests assessment is hyperindividualistic insofar as it not only centres attention on the individual patient but also precludes consideration of the interests of others. If hyperindividualism 
is applied to the four fictional cases in box 1, Sarah's best interests should be determined without consideration of the ways in which respite care might benefit her daughter and John's best interests should be determined without reference to the interests of those with whom he shares a ward. In the cases of Lucy and Ali, the best interests assessment could entirely steer clear of the complications of the respective families.

We believe that the hyperindividualistic interpretation of best interests is mistaken. The case of the single parent shows that there are circumstances where the interests of one person cannot be determined ethically without considering the interests of someone else. We also argue it is a mistaken interpretation of the law, out of keeping with recent judicial rulings, and inconsistent with Department of Health guidelines regarding organ donation.

\section{No legal requirement for hyperindividualism}

In the absence of a definition of best interests, the Mental Capacity Act specifies a procedure that must be followed to determine best interests. The main elements of this procedure are consultative. For example, the assessor is required to determine, so far as is reasonably possible, the patient's past and present wishes, feelings, beliefs, and values and to consult with the patient's care providers and others interested in the patient's welfare. The point is that the act prescribes factors to be taken into account and sources to be consulted; it does not proscribe anything. Aside from the usual caveats about non-discrimination, the act says nothing about what is not to be taken into account in assessing best interests. It leaves open whether and to what extent the interests and wishes of others might be a factor in assessing best interests.

\section{Lessons from case law}

This open question has been addressed by the courts on several occasions. The most important case before the Mental Capacity Act was Re Y [1997]. There the courts ruled that it was in the best interests of $\mathrm{Y}$, an incompetent adult, to undergo medical procedures to donate bone marrow to her sister. In this case the benefit to $\mathrm{Y}$ came entirely by way of the benefit to someone else: by prolonging the life of the sister, the medical procedure brought "emotional, psychological and social benefit [to Y], with minimal detriment." It was only by taking account of the benefit to the sister that Y's own best interests could be determined.

Some have taken the view that the new act precludes this sort of reasoning. But recent rulings suggest otherwise. One of the early test cases concerned financial rather than medical matters. In Re G (TJ) [2010], the court found it to be in the best interests of Mrs G to pay a maintenance allowance to her adult daughter, largely on the grounds that the resulting benefit to the daughter advanced the known altruistic values and preferences of Mrs G herself. As with our case of the single parent, determination of Mrs G's best interests requires us to consider the interests of someone else. Rulings of this sort show that the courts have been reluctant to adopt the hyperindividualistic approach in applying the best interests provisions of the Mental Capacity Act. $^{5}$

\section{Best interests assessments for organ donors}

Perhaps the best way to appreciate the limits of hyperindividualism is to recognise its absurd consequences when carried through to its logical conclusion. Suppose that a registered organ donor arrives at the hospital with a catastrophic brain injury. In the course of emergency treatment there comes a point when further active medical intervention is deemed futile, although the patient may well live for several hours or even days. In such a circumstance it is perfectly appropriate for clinical priorities to shift: if there is no prospect of recovery, the clinical task is to maximise the chances for successful donation. Even in such extreme circumstances, however, the law of best interests still applies. We are here treating an incapacitated patient; medical decisions undertaken on his behalf must be made in his best interests.

The Department of Health publishes guidelines concerning such circumstances and has specifically addressed the question as to whether medical manoeuvres undertaken for the benefit of the organ recipient are allowable under a best interests assessment of the incapacitated donor. Its answer is rightly "yes." ${ }^{\circ 6}$ But if we were to adhere strictly to a hyperindividualist view we would reach the absurd conclusion that the determination of the donor's best interest should take no heed of the interests of the organ recipient-despite the fact that the patient's expressed intention is to be a donor.

\section{Individualism without hyperindividualism}

We have highlighted the inadequacy of hyperindividualistic interpretations of best interests. The good for one is often a function of the good of others; a responsible assessment of best interests can and should take those other goods into account when it is practical to do so. Guidance that suggests otherwise should be revised (box 2).

But it is also critical to recognise that best interests can be understood individualistically without succumbing to hyperindividualism. The Mental Capacity Act provides that treatment undertaken on behalf of an incapacitated patient must be undertaken in the patient's best interests. But provided that a benefit to a third party can be shown to advance the best interests of the patient, it is both ethical and legal to take it into account. In assessing the best interests of patients like Sarah, John, Lucy and Ali, clinicians should therefore be ready and willing to "take the blinkers off," recognising that the best interests of the patient may in some cases be decisively shaped by the best interests of someone else.

Contributors and sources: The authors comprise the research staff of the Essex Autonomy Project, an interdisciplinary research and knowledge exchange initiative at the University of Essex, investigating the ideal of self determination in human affairs, particularly in the vocations of care. VA has a background in social care and AS is a lawyer with expertise in international comparative law of medicine and psychiatry. The analysis was undertaken in close collaboration with doctors, judges, lawyers, social workers, and emergency services staff who have contributed to workshops and training modules on the law and ethics of best interests assessment. The idea for the article emerged in discussion between WM and FF; WM wrote the article and is its guarantor; scenarios were proposed and refined by $\mathrm{EH}$; TO and AS did the literature search; and FF and VA contributed case law materials. All authors participated in the review of successive drafts of the article and made substantial contributions to its final version. 


\section{Box 1: Case studies: what should be included in best interest decisions?}

Sarah

Sarah is an 87 year old woman with dementia. She is cared for at home by her daughter, who is recovering from minor surgery. The daughter's general practitioner suggests that Sarah might have a short stay in a care home in order to allow the daughter to recover fully. Sarah's son objects, stating that a stay in the care home would be too distressing for his mother but that he cannot help with her care himself. Can the interests of the daughter enter into an assessment of Sarah's best interests?

John

John is a 33 year old war veteran with a brain tumour. Recently he has begun to have psychotic episodes, some of which have resulted in angry outbursts. Others on the ward find the outbursts distressing. A psychiatrist recommends an oral antipsychotic drug, but John's family are worried that it may sedate him too much and could shorten his life. Can the interests of other patients on the ward enter into a determination of John's best interests?

\section{Lucy}

Lucy is a 46 year old mother of three with advanced ovarian cancer and has only a few days to live. She is cared for at home by her GP and family. Lucy's husband has asked the GP to tell Lucy the truth about the situation. Both the husband and the GP believe that this could encourage a more open sharing that would make it easier for the children to come to terms with Lucy's death. But Lucy insists that she does not want to discuss the matter. Are the interests of the children relevant in an assessment of Lucy's best interests?

Ali

Ali, a 67 year old man, is admitted to a hospice unconscious and dying. He has an intravenous drip in place, swollen legs, and breathlessness due to heart failure from fluid overload. The hospice doctor and some of the family want to stop the drip and just give mouth care for comfort. However, the eldest son threatens to remove Ali and report the doctor for trying to kill his father by dehydration. Stopping the drip would benefit Ali and therefore comfort most of the family. Must the assessment of Ali's best interests navigate the conflicts among the family?

\section{Box 2: Revised guidance definition of best interests}

Anything done for a person who cannot make decisions for themselves must be in their best interests. This means thinking about what is best for the person. The interests and preferences of other people can be considered only insofar as they affect the interests of the person without capacity.

\section{Box 3: Guidance on case studies}

Sarah

An assessment of the best interests of Sarah, who is 87 and has dementia, must take into account the needs of her carer, which in this case are arguably decisive. Respite care for the daughter is necessary to secure Sarah's long term interests; the clinical team should help the son recognise this fact, but should be prepared to override his objections.

John

The interests of the other patients on the ward where John is being treated for a brain tumour that is causing psychotic episodes are relevant to John's best interests, though they may not be decisive. If distress to other patients causes John to become isolated or makes his stay unworkable, then treatment that fosters better relationships may benefit John. Such considerations should be taken into account along with the family's concerns; they would not justify sedation.

Lucy

The children's interests may well be decisive in determining the best interests of Lucy, who has only a few days to live but doesn't want to discuss her prognosis. The decision depends on the nature of their relationship and the degree of distress that a frank conversation may occasion. Practical experience shows that the anxiety of dying patients about such conversations can often be managed. With proper support, Lucy may realise that the process has benefits for her both by helping the children and by increasing her own psychological wellbeing.

\section{Ali}

Ali is unconscious and dying from heart failure, but that does not obviate the need to consider his best interests. If he valued family peace and consensus, then the effect that removing the intravenous drip against the wishes of his eldest son will have on the family has to be taken into account in managing end of life care. Clinicians may be understandably reluctant to wade into family conflicts, but a degree of strategic intervention may be a necessary part of acting in Ali's best interests.

Competing interests All authors have completed the ICMJE unified declaration form at www.icmje.org/coi_disclosure.pdf (available on request from the corresponding author) and declare: research funded by a grant from the Arts and Humanities Research Council; no financial relationships with any organisations that might have an interest in the submitted work in the previous three years, no other relationships or activities that could appear to have influenced the submitted work. Provenance and peer review: Not commissioned; externally peer reviewed.

1 Holman A, Moore S. Making decisions: an easyread guide. 2nd ed. Office of the Public Guardian, 2007
2 Mental Health Foundation. Banking on good decisions: how can the Mental Capacity Act help you with your bank, building society or post office account? Mental Health Foundation, 2008.

3 Essex Autonomy Project. Best interest decision-making: legal, ethical and clinical issues: a digest. 2011. http://autonomy.essex.ac.uk/best-interest-decision-making-legal-ethicaland-clinical-issues.

4 Berger B, Berger PL. The war over the family: capturing the middle ground. Hutchison, 1983.

5 Herring J, Foster C. Welfare means relationality, virtue and altruism. Legal Studies 2012 April 4. http://onlinelibrary.wiley.com/doi/10.1111/j.1748-121X.2012.00232.x/abstract.

6 Department of Health. Legal issues relevant to non-heartbeating organ donation. DH 2009.

Accepted: 13 November 2012

Cite this as: BMJ 2012;345:e8007

(c) BMJ Publishing Group Ltd 2012 